\title{
IL-10 promoter SNPs and susceptibility to leprosy in ethnic groups from southwest China
}

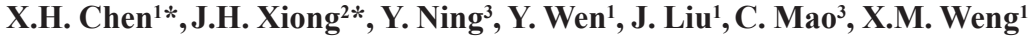 \\ and J.C. Gu$^{1}$ \\ ${ }^{1}$ Beijing Tropical Medicine Research Institute, Beijing Friendship Hospital, \\ Capital Medical University, Beijing, China \\ ${ }^{2}$ People's Hospital of Sichuan, Chengdu, Sichuan, China \\ ${ }^{3}$ Dermatology and Venereology Institute, Sichuan Provincial People's Hospital, \\ Chengdu, Sichuan, China \\ *These authors contributed equally to this study. \\ Corresponding authors: X.M. Weng / J.C. Gu \\ E-mail: wengxiaoman@sina.com
}

Genet. Mol. Res. 12 (3): 2876-2885 (2013)

Received August 1, 2012

Accepted October 18, 2012

Published August 12, 2013

DOI http://dx.doi.org/10.4238/2013.August.12.3

\begin{abstract}
The purpose of this study was to determine whether interleukin-10 (IL-10) promoter polymorphisms are associated with leprosy or their subtypes in ethnic groups from southwest China. Genotyping using TaqMan ${ }^{\circledR}$ SNP Genotyping Master Mix and ABI 7500 real-time PCR system was performed for IL-10 T3575A, G2849A, C2763A, A1082G, C819T, and C592A in 189 healthy controls $(40 \pm 18$ years $)$ and 193 patients $(46 \pm 18$ years $)$ with leprosy [multibacillary, $\mathrm{N}=131$; paucibacillary $(\mathrm{PB}), \mathrm{N}=$ 62]. The allelic frequencies of $-2763 \mathrm{C}(97.9$ vs $94.0 \%, \mathrm{P}=0.0074)$ and $-1082 \mathrm{~A}(92.8$ vs $88.6 \%, \mathrm{P}=0.0452)$ in leprosy patients were significantly higher than in control subjects. The genetic frequency of -2763CC and -1082AA was not only significantly higher among leprosy patients than among control subjects [odds ratio $(\mathrm{OR})=$ $3.33,95 \%$ confidence interval $(95 \% \mathrm{CI})=1.39-7.99, \mathrm{P}=0.0071$
\end{abstract}


and $\mathrm{OR}=1.76,95 \% \mathrm{CI}=1.02-3.03, \mathrm{P}=0.0420$, respectively $]$ but also significantly higher among $\mathrm{PB}$ patients than among control subjects $(\mathrm{OR}=2.46,95 \% \mathrm{CI}=1.22-4.96, \mathrm{P}=0.0115$ and $\mathrm{OR}=$ $5.58,95 \% \mathrm{CI}=2.06-15.12, \mathrm{P}=0.0007$, respectively). The frequency of IL-10 haplotype 3575A/2849G/2763A/1082G/819C/592C was significantly higher among leprosy patients $(\mathrm{OR}=5.57,95 \% \mathrm{CI}=$ $1.13-27.52, \mathrm{P}=0.0351)$ and $\mathrm{PB}$ patients $(\mathrm{OR}=10.5,95 \% \mathrm{CI}=1.36$ $81.05, \mathrm{P}=0.0241)$ than among control subjects. IL-10 promoter $-2763 \mathrm{C} / \mathrm{CC},-1082 \mathrm{~A} / \mathrm{AA}$ and haplotype $3575 \mathrm{~A} / 2849 \mathrm{G} / 2763 \mathrm{~A} / 1082$ $\mathrm{G} / 819 \mathrm{C} / 592 \mathrm{C}$ are associated with susceptibility to leprosy and the PB subtype in southwest China.

Key words: Genotyping; Haplotype analysis; IL-10 gene promoter; Single nucleotide polymorphism

\section{INTRODUCTION}

Leprosy is a chronic disease induced by Mycobacterium leprae, which infects macrophages and Schwann cells and causes disabling nerve injury in up to one-third of patients (Richardus and Habbema, 2007). However, only an estimated $0.1-1 \%$ of individuals exposed to M. leprae develop the disease (Bayley et al., 2004), suggesting the presence of genetic factors that predispose certain individuals to this infection.

Interleukin (IL)-10 is an important anti-inflammatory and immunosuppressive cytokine produced primarily by monocytes and lymphocytes. IL-10 downregulates the expression of T helper 1 cytokines, major histocompatibility complex class II antigens, and costimulatory molecules on macrophages (Sabat, 2010). It also enhances B-cell survival, proliferation, and antibody production (Sabat, 2010). In humans, the IL-10 gene is located within chromosome 1 (1q32) and consists of 5 exons producing a protein of 178 amino acids that functions as a homodimer (Sabat, 2010). IL-10 promoter single nucleotide polymorphisms (SNPs) have been defined as markers for susceptibility and resistance to diseases such as systemic lupus erythematosus (Chong et al., 2004), cancer (Shih et al., 2005; Wei et al., 2007; Wang et al., 2012), mycobacterium infections, and leprosy (Santos et al., 2002; Fitness et al., 2004; Moraes et al., 2004; Malhotra et al., 2005; Franceschi et al., 2009). SNPs and microsatellites in the IL-10 promoter region form several haplotypes that are associated with deferential levels of IL-10 production (Eskdale et al., 1999). The haplotypes of distal and proximal SNPs of the IL-10 promoter regulate IL-10 secretion differentially by influencing the transcription level (Mörmann et al., 2004).

When leprosy bacteria invade the body, they stimulate the monocyte-macrophage cell system of the host, which includes both innate and adaptive immune responses. Monocytemacrophages undertake phagocytosis of leprosy bacteria via IL-10/IL-12 regulation of T-cell cytokine secretion patterns to influence anti-leprosy immunity. Thus, IL-10 plays an important role in leprosy pathogenesis and disease progression. The aim of this study was to evaluate the distribution of IL-10 promoter SNPs (T3575A, G2849A, C2763A, A1082G, C819T, and C592A), their genetic and allelic frequencies, and haplotype association and estimate linkage disequilibrium between ethnic healthy participants and leprosy patients in southwest China, in which the majority of the Chinese leprosy population lives. 


\section{SUBJECTS AND METHODS}

\section{Study subjects}

Healthy volunteers $(\mathrm{N}=189 ; 40 \pm 18$ years $)$ and individuals with leprosy $(\mathrm{N}=$ $193 ; 46 \pm 18$ years) were recruited from Sichuan and Yunnan Provinces. The sample represented 12 tribes, including 3 major nationalities such as Yi, Miao, and Zhuang. Healthy subjects in the Yi, Miao, and Zhuang groups numbered 109, 16, and 27, respectively. Individuals with leprosy in the Yi, Miao, and Zhuang groups numbered 105, 39, and 39, respectively. Demographic data for another 9 tribes is not shown. The healthy controls were subjects from Sichuan and Yunnan Provinces with similarly stratified structures and the same area, age, gender, and ethnic composition as those of the leprosy patients but without any relationship to them. Healthy volunteers were excluded from the study if they had tuberculosis, leprosy (without M. leprae or Mycobacterium lepromatosis), or other severe diseases. Leprosy patients were diagnosed through physical examination and standard histopathologic examination of affected skin lesions. The classification of leprosy was based on clinical and histological criteria published by Ridley and Jopling (1966). This study was approved by the Ethics Committee of the Beijing Friendship Hospital Affiliated with the Capital Medical University. Healthy volunteers and leprosy patients were recruited and examined at the Beijing Friendship Hospital. Informed consent was obtained from each participant.

\section{Blood sample collection and DNA extraction}

Blood samples were withdrawn from a peripheral vein and placed in ethylenediaminetetraacetic acid-containing tubes. DNA was extracted from the patient samples using a QIAamp Blood Kit (Becton Dickinson, Franklin Lakes, NJ, USA) following manufacturer instructions, and DNA concentration was determined with a measurement of ocular density at $260 \mathrm{~nm}$. DNA was stored at $-20^{\circ} \mathrm{C}$ until amplification.

\section{TaqMan ${ }^{\circledR}$ SNP genotyping}

Genotyping of IL-10 gene promoter SNPs T3575A, A1082G, C819T, and C592A was performed using TaqMan ${ }^{\circledR}$ SNP Genotyping Master Mix (Applied Biosystems, Foster City, CA, USA) and the ABI 7500 real-time polymerase chain reaction (PCR) system (Applied Biosystems). The final reaction volume for PCR was $10 \mu \mathrm{L}$, which contained $1 \mu \mathrm{L} 10 \mathrm{ng} / \mu \mathrm{L}$ genomic DNA, $5 \mu \mathrm{L}$ TaqMan ${ }^{\circledR}$ universal PCR master mix, $0.5 \mu \mathrm{L} 200 \mathrm{nM}$ VIC/FAM-labeled probe, and $3.5 \mu \mathrm{L}$ double-distilled water. The probes were designed according to the Human Pre-Designed Assays (Applied Biosystems), and probe sequences are indicated in Table 1. PCR amplification was carried out on 96-well plates each containing wild-type samples (e.g., 3575T/T), heterozygous samples (e.g., 3575T/A), and homozygous samples (e.g., 3575A/A) of unknown genotype as positive controls and no-template controls. Thermal cycle conditions were as follows: $95^{\circ} \mathrm{C}$ for $10 \mathrm{~min}$, and 40 cycles of $92^{\circ} \mathrm{C}$ for $15 \mathrm{~s}$ and $60^{\circ} \mathrm{C}$ for $1 \mathrm{~min}$. Reactions were analyzed using the Allelic Discrimination Sequence Detection Software from Applied Biosystems. 
Table 1. Primer and probe sequences used for IL-10 promoter single nucleotide polymorphisms (SNPs).

\begin{tabular}{|c|c|c|}
\hline SNPs & RS (NCBI) & Sequence of SNPs \\
\hline IL-10 T3575A & rs 1800890 & $\begin{array}{l}\text { CCCAGTACATCCCCCACTGGAAAAAT } \\
\text { [A/T]CATTTAAAATCAGTATAATAAGCAT }\end{array}$ \\
\hline IL-10 G2849A & rs6703630 & $\begin{array}{l}\text { GGTCTCGATCTCCTGACCTTATGATC[C/T] } \\
\text { GCCCGCCTTGGCCTCCCAGAGTGCT }\end{array}$ \\
\hline IL-10 C2763A & rs6693899 & $\begin{array}{l}\text { AGGCGCCTGGCACCACGCCCGGCTAA } \\
\text { [G/T]TTTTTTTATTTTTTTTTGTATTTTT }\end{array}$ \\
\hline IL-10 A1082G & rs 1800896 & $\begin{array}{l}\text { ACAACACTACTAAGGCTTCTTTGGGA } \\
\text { [A/G]GGGGAAGTAGGGATAGGTAAGAGGA }\end{array}$ \\
\hline IL-10 C819T & rs 1800871 & $\begin{array}{l}\text { GGTGTACCCTTGTACAGGTGATGTAA } \\
\text { [C/T]ATCTCTGTGCCTCAGTTTGCTCACT }\end{array}$ \\
\hline IL-10 C592A & rs 1800872 & $\begin{array}{l}\text { GGAACACATCCTGTGACCCCGCCTGT } \\
\text { [A/C]CTGTAGGAAGCCAGTCTCTGGAAAG }\end{array}$ \\
\hline TaqMan SNP genotyping & Probes (ABI) & Sequence of probes \\
\hline IL-10 T3575A & C__8828790_10[VIC/FAM] & $\begin{array}{l}\text { ATGCTTATTATACTGATTTTAAATG } \\
\text { [A/T]ATTTTTCCAGTGGGGGATGTACTGG }\end{array}$ \\
\hline IL-10 A1082G & C__1747360_10[VIC/FAM] & $\begin{array}{l}\text { TCCTCTTACCTATCCCTACTTCCCC } \\
{[\text { T/C]TCCCAAAGAAGCCTTAGTAGTGTTG }}\end{array}$ \\
\hline IL-10 C819T & C__ $1747362 \_10[\mathrm{VIC} / \mathrm{FAM}]$ & $\begin{array}{l}\text { AGTGAGCAAACTGAGGCACAGAGAT } \\
{[\text { A/G]TTACATCACCTGTACAAGGGTACAC }}\end{array}$ \\
\hline IL-10 C592A & C__1747363_10[VIC/FAM] & $\begin{array}{l}\text { CTTTCCAGAGACTGGCTTCCTACAG[T/G] } \\
\text { ACAGGCGGGGTCACAGGATGTGTTC }\end{array}$ \\
\hline PCR-sequencing & Primers & Sequence of primers \\
\hline IL-10 T3575A (228 bp) & $\begin{array}{l}\text { Forward } \\
\text { Reverse }\end{array}$ & $\begin{array}{l}\text { 5'-GGT TTT CCT TCA TTT GCA GC-3' } \\
\text { 5'-ACA CTG TGA GCT TCT TGA GG-3' }\end{array}$ \\
\hline IL-10 G2849A/C2763A (667 bp) & $\begin{array}{l}\text { Forward } \\
\text { Reverse }\end{array}$ & $\begin{array}{l}\text { 5'-TTCAGCAAATGGCTTGAGAT-3' } \\
\text { 5'-ATAGGTACCAAGTCTGGCCCTTGGAA-3' }\end{array}$ \\
\hline IL-10 C819T/C592A (588 bp) & $\begin{array}{l}\text { Forward } \\
\text { Reverse }\end{array}$ & $\begin{array}{l}\text { 5'-CACAAATCCAAGACAACACT-3' } \\
\text { 5'-TATCCTCAAAGTTCCCAAGC-3' }\end{array}$ \\
\hline
\end{tabular}

\section{PCR sequencing}

PCR sequencing was performed to confirm the results of TaqMan ${ }^{\circledR}$ SNP genotyping for SNPs T3575A, A1082G, C819T, and C592A and to detect the additional SNPs G2849A and C2763A. PCR primers are shown in Table 1. DNA amplification was performed using GoTaq Green Master Mix (Promega, Madison, WI, USA) in a final reaction volume of $50 \mu \mathrm{L}$, containing $3 \mu \mathrm{L}$ DNA template, $25 \mu \mathrm{L} 2 \mathrm{X}$ GoTaq Green Master Mix, $21 \mu \mathrm{L}$ double-distilled water (all from Promega), and $1 \mu \mathrm{L} 10 \mu \mathrm{M}$ of each primer synthesized by Sangon Biotech Co., Ltd. (Shanghai, China). After a first denaturation step for $7 \mathrm{~min}$ at $94^{\circ} \mathrm{C}$, the amplification was performed in 40 sequential cycles at $93^{\circ} \mathrm{C}$ for $1 \mathrm{~min}, 60^{\circ} \mathrm{C}$ for $1 \mathrm{~min}$, and $72^{\circ} \mathrm{C}$ for $1 \mathrm{~min}$. At the end of amplification, the samples were heated to $72^{\circ} \mathrm{C}$ for $10 \mathrm{~min}$ and then maintained at $4^{\circ} \mathrm{C}$ until further analysis. Direct sequencing was performed using a Prism 5700 DNA Sequencer from Sangon Biotech Co., Ltd.

\section{Statistical analysis}

The Haploview 4.1 software was used to evaluate the linkage disequilibrium (LD) and carry out chi-square tests between groups for each the SNP. The SAS 9.0 software (SAS Institute, Inc., Cary, NC, USA) was used to determine the odds ratios (ORs) using logistic regression. All $\mathrm{P}$ values were two-sided and considered significant if they were less than 0.05 . 


\section{RESULTS}

\section{Hardy-Weinberg equilibrium (HWE) analysis}

To assess whether IL-10 promoter SNPs were associated with susceptibility or resistance to leprosy, we evaluated 193 leprosy patients and 189 healthy controls for IL-10 promoter SNPs. No significant differences in age or gender were observed between the 2 groups (data not shown). Of the 6 SNPs evaluated, all were in HWE. The accuracy of the genotyping method and the HWE of the 2 populations were examined. The accuracy of TaqMan ${ }^{\circledR}$ SNP genotyping was confirmed with PCR sequencing and ruled out personal and instrument errors. In addition, the genotype frequencies of IL-10 SNPs did not deviate significantly from HWE in either the Sichuan or the Yunnan ethnic healthy populations, indicating that the selected populations were representative of the whole.

\section{Allelic frequency analysis}

Analysis of the allelic distributions of rs1800896 and rs6693899 differed significantly between participants with leprosy and healthy controls (Table 2; $\mathrm{P}=0.0452$ and 0.0074 , respectively). Association was observed between the IL-10 -2763C/-1082A allele and susceptibility to leprosy and paucibacillary (PB) leprosy.

\begin{tabular}{|c|c|c|c|c|c|c|c|c|c|c|c|c|}
\hline & \multicolumn{2}{|c|}{ rs 1800872} & \multicolumn{2}{|c|}{ rs 1800871} & \multicolumn{2}{|c|}{ rs 1800896} & \multicolumn{2}{|c|}{ rs6693899 } & \multicolumn{2}{|c|}{ rs 6703630} & \multicolumn{2}{|c|}{ rs 1800890} \\
\hline & Case & Control & Case & Control & Case & Control & Case & Control & Case & Control & Case & Control \\
\hline A & $\begin{array}{l}267 / 386 \\
(69.2 \%)\end{array}$ & $\begin{array}{l}257 / 376 \\
(68.4 \%)\end{array}$ & - & - & $\begin{array}{l}342 / 386 \\
(88.6 \%)\end{array}$ & $\begin{array}{l}349 / 376 \\
(92.8 \%)\end{array}$ & $\begin{array}{l}23 / 386 \\
(6.0 \%)\end{array}$ & $\begin{array}{c}8 / 376 \\
(2.1 \%)\end{array}$ & $\begin{array}{c}6 / 386 \\
(1.6 \%)\end{array}$ & $\begin{array}{c}2 / 376 \\
(0.5 \%)\end{array}$ & $\begin{array}{l}29 / 386 \\
(7.5 \%)\end{array}$ & $\begin{array}{l}20 / 376 \\
(5.3 \%)\end{array}$ \\
\hline C & $\begin{array}{l}119 / 386 \\
(30.8 \%)\end{array}$ & $\begin{array}{l}119 / 376 \\
(31.6 \%)\end{array}$ & $\begin{array}{l}119 / 386 \\
(30.8 \%)\end{array}$ & $\begin{array}{l}119 / 376 \\
(31.6 \%)\end{array}$ & - & - & $\begin{array}{l}363 / 386 \\
(94.0 \%)\end{array}$ & $\begin{array}{l}368 / 376 \\
(97.9 \%)\end{array}$ & - & - & - & - \\
\hline G & - & - & 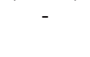 & - & $\begin{array}{l}44 / 386 \\
(11.4 \%)\end{array}$ & $\begin{array}{l}27 / 376 \\
(7.2 \%)\end{array}$ & - & - & $\begin{array}{l}380 / 386 \\
(98.4 \%)\end{array}$ & $\begin{array}{l}374 / 376 \\
(99.5 \%)\end{array}$ & - & - \\
\hline & - & - & $\begin{array}{l}267 / 386 \\
(69.2 \%)\end{array}$ & $\begin{array}{l}257 / 376 \\
(68.4 \%)\end{array}$ & - & - & - & - & - & - & $\begin{array}{l}357 / 386 \\
(92.5 \%)\end{array}$ & $\begin{array}{l}356 / 376 \\
(94.7 \%)\end{array}$ \\
\hline$\chi^{2}$ & $\begin{array}{l}0.06 \\
0.8071\end{array}$ & & $\begin{array}{l}0.06 \\
0.8071\end{array}$ & & 4.011 & & 7.162 & & 1.917 & & 1.523 & \\
\hline & 0.8071 & & 0.8071 & & $0.0452^{*}$ & & $0.0074^{*}$ & & 0.1662 & & 0.2171 & \\
\hline
\end{tabular}

*Significant difference in allele frequency distribution between the patients with leprosy (cases) and healthy controls.

\section{Genotype frequency analysis}

Genotype frequency and logistic regression analyses using wild-type genotypes as dominant and other genotypes as recessive were undertaken next. Specifically, as shown in Table 3, rs $1800896 \mathrm{AG}+\mathrm{GG}$ was associated with a 1.76-fold greater risk of developing leprosy compared with that accompanying rs $1800896 \mathrm{AA}[95 \%$ confidence interval $(95 \% \mathrm{CI})=1.02-3.03, \mathrm{P}$ $=0.0420]$. In addition, the rs6693899 CA+AA genotype was associated with a 3.33-fold greater risk of developing leprosy compared with that associated with rs6693899CC $(95 \% \mathrm{CI}=1.39$ 7.99, $\mathrm{P}=0.0071$; see Table 3). Compared with rs1800896AA, rs1800896 AG+GG conferred a 2.46 times greater risk of developing PB leprosy or a mild form of leprosy $(95 \% \mathrm{CI}=1.22$ 4.96, $\mathrm{P}=0.0115$; Table 4). In addition, the rs6693899 CA+AA genotype was associated with a 5.58-fold greater risk of developing PB leprosy compared with the risk associated with the 
rs6693899CC genotype (95\%CI $=2.06-15.12, \mathrm{P}=0.0007)$. An association was found between the IL-10 -2763CC/-1082AA genotype and susceptibility to leprosy and PB leprosy.

\begin{tabular}{|c|c|c|c|c|c|c|}
\hline & Genotype & Case & Control & & OR $(95 \% \mathrm{CI})$ & $\mathrm{P}$ \\
\hline \multirow[t]{3}{*}{ rs1800890 } & TT & $165(85.49 \%)$ & $170(90.43 \%)$ & Reference & 1 & \\
\hline & TA & $27(13.99 \%)$ & $16(8.51 \%)$ & $\mathrm{TA}+\mathrm{AA}$ & $1.60(0.86-3.01)$ & 0.1421 \\
\hline & AA & $1(0.52 \%)$ & $2(1.06 \%)$ & & & \\
\hline \multirow[t]{2}{*}{ rs6703630 } & GG & $187(96.89 \%)$ & $186(98.94 \%)$ & Reference & 1 & \\
\hline & GA & $6(3.11 \%)$ & $2(1.06 \%)$ & GA & $2.98(0.60-14.98)$ & 0.1841 \\
\hline \multirow[t]{3}{*}{ rs6693899 } & $\mathrm{CC}$ & $171(88.60 \%)$ & $181(96.28 \%)$ & Reference & 1 & \\
\hline & $\mathrm{CA}$ & $21(10.88 \%)$ & $6(3.19 \%)$ & $\mathrm{CA}+\mathrm{AA}$ & $3.33(1.39-7.99)$ & $0.0071 *$ \\
\hline & AA & $1(0.52 \%)$ & $1(0.53 \%)$ & & & \\
\hline \multirow{3}{*}{ rs1800896 } & AA & $152(78.76 \%)$ & $163(86.70 \%)$ & Reference & 1 & \\
\hline & AG & $38(19.69 \%)$ & $23(12.23 \%)$ & $\mathrm{AG}+\mathrm{GG}$ & $1.76(1.02-3.03)$ & $0.0420 *$ \\
\hline & GG & $3(1.55 \%)$ & $2(1.06 \%)$ & & & \\
\hline \multirow[t]{3}{*}{ rs1800871 } & $\mathrm{CC}$ & $17(8.81 \%)$ & $20(10.64 \%)$ & Reference & 1 & \\
\hline & $\mathrm{CT}$ & 85 (44.04\%) & $79(42.02 \%)$ & $\mathrm{CT}+\mathrm{TT}$ & $1.23(0.62-2.43)$ & 0.5476 \\
\hline & TT & $91(47.15 \%)$ & $89(47.34 \%)$ & & & \\
\hline \multirow[t]{4}{*}{ rs1800872 } & $\mathrm{CC}$ & $17(8.81 \%)$ & $20(10.64 \%)$ & Reference & 1 & \\
\hline & $\mathrm{CA}$ & $85(44.04 \%)$ & $79(42.02 \%)$ & $\mathrm{CA}+\mathrm{AA}$ & $1.23(0.62-2.43)$ & 0.5476 \\
\hline & AA & $91(47.15 \%)$ & $89(47.34 \%)$ & & & \\
\hline & & $17(8.81 \%)$ & $20(10.64 \%)$ & & & \\
\hline \multirow{5}{*}{ Haplotype $\dagger$} & 111111 & $7(4.00 \%)$ & $9(5.11 \%)$ & Reference & & \\
\hline & 111122 & $141(80.57 \%)$ & $152(86.36 \%)$ & 111122 & $1.19(0.43-3.29)$ & 0.7334 \\
\hline & 111222 & $9(5.14 \%)$ & $4(2.27 \%)$ & 111222 & $2.89(0.62-13.46)$ & 0.1756 \\
\hline & 211222 & $5(2.86 \%)$ & $8(4.55 \%)$ & 211222 & $0.80(0.18-3.57)$ & 0.7738 \\
\hline & 212222 & $13(7.43 \%)$ & $3(1.70 \%)$ & 212222 & $5.57(1.13-27.52)$ & $0.0351 *$ \\
\hline
\end{tabular}

$\mathrm{OR}=$ odds ratio $; 95 \% \mathrm{CI}=95 \%$ confidence interval. $*$ Significantly higher risk of developing leprosy. $\uparrow$ Wild type is 1 , heterozygote and homozygote are $2 ; 112122,112211,112222,121122,211111,211122,211211,212211$, 221211, 222211, and 222222 were eliminated because the counts were under 10 and were unable to yield an interval estimate.

Table 4. Subgroup logistic regression analysis.

\begin{tabular}{|c|c|c|c|c|c|}
\hline & & \multicolumn{2}{|c|}{ MB vs control } & \multicolumn{2}{|c|}{ PB vs control } \\
\hline & & OR $(95 \% \mathrm{CI})$ & $\mathrm{P}$ & OR $(95 \% \mathrm{CI})$ & $\mathrm{P}$ \\
\hline \multirow[t]{2}{*}{ rs 1800890} & Reference & 1 & & 1 & \\
\hline & $\mathrm{TA}+\mathrm{AA}$ & $1.22(0.59-2.52)$ & 0.5888 & $2.51(1.15-5.47)$ & 0.0212 \\
\hline \multirow[t]{2}{*}{ rs6703630 } & Reference & 1 & & 1 & \\
\hline & GA & $1.44(0.2-10.37)$ & 0.7162 & $6.41(1.15-35.9)$ & 0.0345 \\
\hline \multirow[t]{2}{*}{ rs6693899 } & Reference & 1 & & 1 & \\
\hline & $\mathrm{CA}+\mathrm{AA}$ & $2.37(0.89-6.29)$ & 0.0829 & $5.58(2.06-15.12)$ & $0.0007 *$ \\
\hline \multirow[t]{2}{*}{ rs1800896 } & Reference & 1 & & 1 & \\
\hline & $\mathrm{AG}+\mathrm{GG}$ & $1.46(0.79-2.69)$ & 0.2227 & $2.46(1.22-4.96)$ & $0.0115^{*}$ \\
\hline \multirow[t]{2}{*}{ rs 1800871} & Reference & 1 & & 1 & \\
\hline & $\mathrm{CT}+\mathrm{TT}$ & $1.44(0.65-3.19)$ & 0.3678 & $0.94(0.38-2.33)$ & 0.886 \\
\hline \multirow[t]{2}{*}{ rs1800872 } & Reference & 1 & & 1 & \\
\hline & $\mathrm{CA}+\mathrm{AA}$ & $1.44(0.65-3.19)$ & 0.3678 & $0.94(0.38-2.33)$ & 0.886 \\
\hline \multirow[t]{5}{*}{ Haplotype $\dagger$} & Reference & & & & \\
\hline & 111122 & $1.18(0.39-3.64)$ & 0.7677 & $1.21(0.25-5.84)$ & 0.8089 \\
\hline & 111222 & $3.15(0.61-16.31)$ & 0.1715 & $2.25(0.23-22.14)$ & 0.487 \\
\hline & 211222 & $0.68(0.12-3.77)$ & 0.6545 & $1.13(0.13-9.94)$ & 0.9156 \\
\hline & 212222 & $3.6(0.62-21.03)$ & 0.1549 & $10.5(1.36-81.05)$ & $0.0241 *$ \\
\hline
\end{tabular}

$\mathrm{MB}=$ multibacillary leprosy; $\mathrm{PB}=$ paucibacillary leprosy; $\mathrm{OR}=$ odds ratio; $95 \% \mathrm{CI}=95 \%$ confidence interval. *Significantly higher risk of developing leprosy. $†$ Wild type is 1 , heterozygote and homozygote are $2 ; 112122$, 112211, 112222, 121122, 211111, 211122, 211211, 212211, 221211, 222211, and 222222 were eliminated because the counts were under 10 and were unable to yield an interval estimate. 


\section{Haplotype analysis}

Logistic regression analysis revealed that the $3575 \mathrm{~A} / 2849 \mathrm{G} / 2763 \mathrm{~A} / 1082 \mathrm{G} / 819 \mathrm{C} / 92 \mathrm{C}$ haplotype was associated with 5.57-fold greater risk of developing leprosy compared with the risk accompanying the wild-type reference $(95 \% \mathrm{CI}=1.13-27.52, \mathrm{P}=0.0351)$. Furthermore, logistic regression analysis revealed that $3575 \mathrm{~A} / 2849 \mathrm{G} / 2763 \mathrm{~A} / 1082 \mathrm{G} / 819 \mathrm{C} / 592 \mathrm{C}$ increased the risk of developing $\mathrm{PB}$ leprosy 10.5 times compared with risk accompanying the wild-type reference $(95 \% \mathrm{CI}=1.36-81.05, \mathrm{P}=0.0241)$.

\section{LD analysis}

LD analysis was performed to identify possible intra- and intergene interactions among the SNPs (Figure 1). A significant LD was found between rs1800872 and rs $1800871\left(\mathrm{D}^{\prime}=1\right)$; rs1800872 and rs6693899 (D' $\geq 0.99)$; rs1800872 and rs6703630 ( $\left.\mathrm{D}^{\prime} \geq 0.99\right)$; rs1800871 and

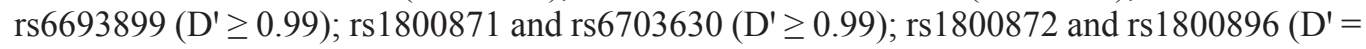
$0.95)$; rs1800871 and rs1800896 ( $\left.\mathrm{D}^{\prime}=0.95\right)$.

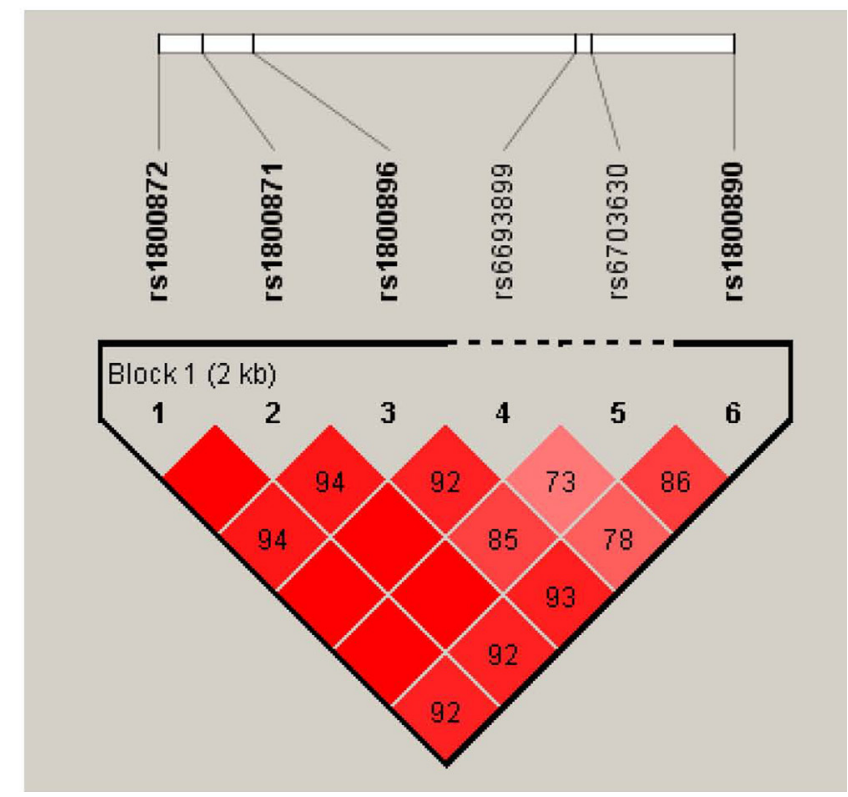

Figure 1. Analysis of haplotype linkage between leprosy patients and controls.

\section{DISCUSSION}

The association of IL-10 promoter SNPs with susceptibility to leprosy has been demonstrated in Brazilian (Santos et al., 2002; Moraes et al., 2004; Franceschi et al., 2009; Pereira et al., 2009), Malawian (Fitness et al., 2004), and Indian populations (Malhotra et al., 2005); however, the frequency and distribution of IL-10 SNPs varies by population (Lazarus et al., 
2002; Torkildsen et al., 2005). Because similar analyses have yet to be undertaken in Chinese populations living in southwest China, in which the majority of leprosy cases are found in China, this study sought to compare the distribution of IL-10 promoter SNPs in leprosy patients and healthy controls. LD analysis revealed complete LD between -819 and -592 loci in both the Sichuan and the Yunnan groups.

The genotype frequencies of IL-10 SNPs did not deviate significantly from HWE for either the Sichuan or the Yunnan ethnic healthy populations, indicating that the selected populations were representative. Furthermore, the samples were selected from healthy individuals of the same ethnicity from southwest China without genetic relationship to the leprosy patients. Therefore, no special selection occurred in the participants of the present study.

Comparison of the allele and genotype frequencies in the Sichuan ethnic healthy population with those cataloged in a public SNP database (http://www.ncbi.nlm.nih.gov/SNP; accessed September 20,2012) showed that the genotype frequencies of most IL-10 promoter polymorphisms were significantly different from those in Caucasian and African populations as well as those in the Han Chinese population. In addition, the IL-10 allele, genotype, and haplotype frequencies in both groups were significantly different than those of other populations, implying genetic heterogeneity between populations.

In the present study, the allele, genotype, and haplotype frequencies between the healthy Chinese individuals from the southwest were compared with those of patients with leprosy from the same region. Logistic regression analysis revealed that the $-3575 \mathrm{~A} /$ $-2849 \mathrm{G} /-2763 \mathrm{~A} /-1082 \mathrm{G} /-819 \mathrm{C} /-592 \mathrm{C}$ haplotype was associated with a 5.57 -fold greater risk of developing leprosy compared with that accompanying the wild-type reference. In a Brazilian population, $-819 \mathrm{C} / \mathrm{T}$ is associated with leprosy susceptibility, and peripheral blood mononuclear cells of $-819 \mathrm{~T}$ carriers stimulated with $M$. leprae antigens produced levels of IL-10 that were lower than those of noncarriers (Pereira et al., 2009).

A Brazilian population and the healthy Chinese group had a similar frequency of the $-3575 \mathrm{~A} /-2849 \mathrm{G} /-2763 \mathrm{C}$ haplotype, which is associated with resistance to leprosy and the development of the severe form of leprosy, multibacillary (MB) leprosy, in Brazilians (Santos et al., 2002). However, the -3575T/-2849A/-2763C haplotype, which is associated with susceptibility to leprosy in Brazilians (Santos et al., 2002), was not observed in the healthy individuals analyzed in the present study.

Compared with data reported from an Indian population, the data for the Chinese population analyzed in the present study showed a high frequency of the IL-10 -3575T/-2849G/ $-2763 \mathrm{C} /-1082 \mathrm{~A} /-819 \mathrm{~T} /-592 \mathrm{~A}$ haplotype, which is associated with resistance to leprosy and the development of severe MB leprosy in Indians (Malhotra et al., 2005). In addition, a low frequency of the IL-10 -3575T/-2849G/-2763C/-1082A/-819C/-592C haplotype, which is associated with risk for a severe form of leprosy in Indians (Malhotra et al., 2005), was observed in the present study.

LD analysis revealed that IL-10 polymorphisms $-819 \mathrm{C} / \mathrm{T}$ and $-592 \mathrm{C} / \mathrm{A}$ had complete LD in healthy Sichuan and Yunnan ethnic participants. A Malawi population study comparing 349-362 leprosy patients (90\% PB) with 191-215 controls for IL-10 promoter SNPs (-1082, $-819,-592$ ) related to leprosy susceptibility found no meaningful SNPs (Fitness et al., 2004). However, in a population study of 282 leprosy patients (140 MB and $142 \mathrm{~PB}$ ) and 266 controls in India examining IL-10 promoter to SNPs (-3575, -2849, -2763, -1082, -819, -592), Malhotra et al. (2005) have shown that -819TT-592AA loci in case-control, PB-control, and 
inter-MB-control groups are significantly different $(\mathrm{P}=0.0002,0.0002$, and 0.001 and 0.0004 , 0.0001 , and 0.01 , respectively). Pereira et al., (2009) have reported that studies of IL-10 promoters to SNPs $(-3575,-2849,-2763,-1082,-819)$ and leprosy susceptibility in a Brazilian population (374 leprosy, 380 controls) combined with meta-analysis results suggest that the -819T genotype-819TT allele is a predisposing factors of leprosy $(\mathrm{OR}=1.44$ for TT/CT $v s$ $\mathrm{CC} ; \mathrm{P}=0.026)$. A genotyping study of IL-10 SNP promoters $(-3575,2849,-2763-1082,-819)$ in a healthy Brazilian population of Dutch whites has found that the carrying frequency of SNPs and haplotypes in the 2 populations (the Brazilian versus the Dutch populations) were significantly different (Moraes et al., 2003), suggesting that genetic heterogeneity may be one of the reasons for the difficulty in drawing similar conclusions about susceptibility genes across populations.

In addition to SNPs, various haplotypes can also affect IL-10 secretion. Eskdale et al. (1999) have reported an IL-10 promoter SNPs study of 56 Dutch European families in which the proximal IL-10 promoter SNP -1082G/-819C/-592C haplotype showed relatively low secretion, whereas the $1082 \mathrm{~A} /-819 \mathrm{C} /-592 \mathrm{C}$ was the relatively high-secretion haplotype. Gibson et al. (2001) have conducted a systemic lupus erythematosus study in which the distal IL-10 promoter SNP IL-10 -3575T/-2849G/-2763C haplotype was shown to be related to IL-10 hypersecretion, and the $-3575 \mathrm{~A} /-2849 \mathrm{G} /-2763 \mathrm{~A}$ and $-3575 \mathrm{~A} /-2849 \mathrm{~A} /-2763 \mathrm{~A}$ haplotypes were related to low IL-10 secretion. Moreover, the distal SNPs have a greater effect on IL-10 secretion than the proximal SNPs (Gibson et al., 2001). IL-10 promoter to the SNPs and haplotype may be associated with high IL-10 secretion and leprosy susceptibility, but various population groups with leprosy and disease-type relationships as well as functional studies have yet to be thoroughly explored.

In conclusion, in this study, we analyzed the frequency of IL-10 promoter polymorphisms in leprosy patients and healthy controls living in southwest China. Further studies are necessary to determine the role of IL-10 gene polymorphisms among various regions and ethnic groups and their association with various IL-10-related diseases, including leprosy.

\section{Conflicts of interest}

The authors declare no financial conflict with any person or organization.

\section{ACKNOWLEDGMENTS}

Research supported by grants from the Young Scientists Fund of Beijing Health Bureau (\#QN2009-003) and Co-Funding of the Basic-Clinic Scientific Research Cooperation Foundation of Capital Medical University and Li Huan Ying Medical Foundation (\#09JL-L 05).

\section{REFERENCES}

Bayley JP, Ottenhoff TH and Verweij CL (2004). Is there a future for TNF promoter polymorphisms? Genes Immun. 5: 315-329.

Chong WP, Ip WK, Wong WH, Lau CS, et al. (2004). Association of interleukin-10 promoter polymorphisms with systemic lupus erythematosus. Genes Immun. 5: 484-492.

Eskdale J, Keijsers V, Huizinga T and Gallagher G (1999). Microsatellite alleles and single nucleotide polymorphisms (SNP) combine to form four major haplotype families at the human interleukin-10 (IL-10) locus. Genes Immun. 1: 151-155.

Fitness J, Floyd S, Warndorff DK, Sichali L, et al. (2004). Large-scale candidate gene study of leprosy susceptibility in the Karonga district of northern Malawi. Am. J. Trop. Med. Hyg. 71: 330-340. 
Franceschi DS, Mazini PS, Rudnick CC, Sell AM, et al. (2009). Influence of TNF and IL10 gene polymorphisms in the immunopathogenesis of leprosy in the south of Brazil. Int. J. Infect. Dis. 13: 493-498.

Gibson AW, Edberg JC, Wu J, Westendorp RG, et al. (2001). Novel single nucleotide polymorphisms in the distal IL-10 promoter affect IL-10 production and enhance the risk of systemic lupus erythematosus. J. Immunol. 166: 3915-3922.

Lazarus R, Klimecki WT, Palmer LJ, Kwiatkowski DJ, et al. (2002). Single-nucleotide polymorphisms in the interleukin-10 gene: differences in frequencies, linkage disequilibrium patterns, and haplotypes in three United States ethnic groups. Genomics 80: 223-228.

Malhotra D, Darvishi K, Sood S, Sharma S, et al. (2005). IL-10 promoter single nucleotide polymorphisms are significantly associated with resistance to leprosy. Hum. Genet. 118: 295-300.

Moraes MO, Santos AR, Schonkeren JJ, Vanderborght PR, et al. (2003). Interleukin-10 promoter haplotypes are differently distributed in the Brazilian versus the Dutch population. Immunogenetics 54: 896-899.

Moraes MO, Pacheco AG, Schonkeren JJ, Vanderborght PR, et al. (2004). Interleukin-10 promoter single-nucleotide polymorphisms as markers for disease susceptibility and disease severity in leprosy. Genes Immun. 5: 592-595.

Mörmann M, Rieth H, Hua TD, Assohou C, et al. (2004). Mosaics of gene variations in the Interleukin-10 gene promoter affect interleukin-10 production depending on the stimulation used. Genes Immun. 5: 246-255.

Pereira AC, Brito-de-Souza VN, Cardoso CC, Dias-Baptista IM, et al. (2009). Genetic, epidemiological and biological analysis of interleukin-10 promoter single-nucleotide polymorphisms suggests a definitive role for $-819 \mathrm{C} / \mathrm{T}$ in leprosy susceptibility. Genes Immun. 10: 174-180.

Richardus JH and Habbema JD (2007). The impact of leprosy control on the transmission of M. leprae: is elimination being attained? Lepr. Rev. 78: 330-337.

Ridley DS and Jopling WH (1966). Classification of leprosy according to immunity. A five-group system. Int. J. Lepr. Other Mycobact. Dis. 34: 255-273.

Sabat R (2010). IL-10 family of cytokines. Cytokine Growth Factor Rev. 21: 315-324.

Santos AR, Suffys PN, Vanderborght PR, Moraes MO, et al. (2002). Role of tumor necrosis factor-alpha and interleukin-10 promoter gene polymorphisms in leprosy. J. Infect. Dis. 186: 1687-1691.

Shih CM, Lee YL, Chiou HL, Hsu WF, et al. (2005). The involvement of genetic polymorphism of IL-10 promoter in non-small cell lung cancer. Lung Cancer 50: 291-297.

Torkildsen O, Utsi E, Harbo HF, Mellgren SI, et al. (2005). Ethnic variations of IL-10 polymorphisms in a Sami and Norwegian population. Scand. J. Immunol. 62: 71-74.

Wang J, Ding Q, Shi Y, Cao Q, et al. (2012). The interleukin-10-1082 promoter polymorphism and cancer risk: a metaanalysis. Mutagenesis 27: 305-312.

Wei YS, Kuang XH, Zhu YH, Liang WB, et al. (2007). Interleukin-10 gene promoter polymorphisms and the risk of nasopharyngeal carcinoma. Tissue Antigens 70: 12-17. 